\title{
LA PROHIBICIÓN DE LA PRESCRIPCIÓN O LA IMPRESCRIPTIBILIDAD COMO REFORMA PENAL CONSTITUCIONAL
}

\section{THE PROHIBITION OF THE PRESCRIPTION OR IMPRESCRIPTIBILITY AS A CONSTITUTIONAL CRIMINAL REFORM}

\author{
Alexei Dante Sáenz Torres ${ }^{1}$ \\ Docente \\ Universidad Nacional Mayor de San Marcos \\ alexeisaenz@gmail.com
}

Perú

\section{SUMARIO}

- Introducción

- Antecedentes constitucionales

- Algunos fundamentos de la imprescriptibilidad

- Observaciones a la reforma o enmienda penal constitucional

- El tratamiento de la reforma aprobada

- Las antinomias o incompatibilidades entre la primera parte del último párrafo y la segunda parte del último párrafo del art. 41 de la Constitución de 1993.

- La mención al principio de legalidad

- ¿Qué implica la fórmula “supuestos más graves"?

- El caso del proyecto de ley No 2114/2017CR

- ¿La prohibición de la prescripción o imprescriptibilidad de la acción penal y de la ejecución de la pena?

- Conclusiones

\section{RESUMEN}

El presente artículo tiene como propósito analizar la última reforma penal constitucional de la Ley $\mathrm{N}^{\circ} 30650$, mediante la cual se reguló la prohibición de la prescripción penal o la imprescriptibilidad penal para algunos funcionarios públicos que realicen delitos contra la administración pública, y establecer las compatibilidades con la legislación vigente, así como la viabilidad o no de su aplicación inmediata. Para ello se presentan diversas propuestas de solución a fin de considerar a la hora que se pretenda reglamentar la regla jurídica de aplicación inmediata a través de la ley de regulación en el Código Penal de 1991.

\section{ABSTRACT}

The purpose of this article is to analyze the latest constitutional criminal reform of Law $\mathrm{N} \circ 30650$, which regulated the prohibition of criminal prescription or the statute of limitations for some public officials who carry out crimes against the public administration, and establish compatibilities with the current legislation, as well as the feasibility or not of its immediate application. To that end, various solution proposals are presented in order to consider at the time that the legal rule of immediate application is to be regulated through the regulation law in the 1991 Penal Code.

\section{PALABRAS CLAVES}

Prohibición de la prescripción, Imprescriptibilidad, Prescripción de la acción penal, Prescripción de la ejecución de la pena.

1 Profesor Principal en la UNMSM en el pregrado y el posgrado, profesor contratado en la Escuela de Posgrado de la USMP y profesor contratado en la UNFV y en la AMAG. 


\section{KEY WORDS}

Prohibition of prescription, Imprescriptibility, prescription of the criminal action, Prescription of the execution of the penalti.

\section{INTRODUCCIÓN}

La aprobación de la enmienda o reforma penal constitucional, mediante la ley $\mathrm{N}^{\circ} 30650$, por parte del Congreso de la República, reguló la imprescriptibilidad penal para determinados delitos graves de contra la administración pública.

Sin embargo, mientras los políticos que aprobaron la reforma que requirió de dos votaciones según las disposiciones de la Constitución de 1993, previo mea culpa, se jactaban con señalar que se trató de la reforma más relevante en materia de anticorrupción a la Constitución de 1993 la academia postuló el siguiente problema: ¿si la regla penal constitucional regulada en el último párrafo del art. 41 de la Constitución es de aplicación directa o requiere de una regla penal legal derivada o de desarrollo?

Así el presente artículo tiene la finalidad de dar respuesta a esta interrogante, como una contribución de la academia para con el país, no se pretende profundizar el estudio de lo que es la imprescriptibilidad que ya lo hemos abordado anteriormente en otro trabajo, cuyos alcances se mantiene ${ }^{2}$.

\section{ANTECEDENTES CONSTITUCIONALES}

La reforma constitucional reguló la imprescriptibilidad penal, constituyéndose en el primer precedente en la historia de las anteriores constituciones que ha tenido el Estado, pues es la primera vez que se incorporó esta institución a nivel penal constitucional ${ }^{3}$,

2 Sobre la imprescriptibilidad véase nuestro artículo Algunas reflexiones a propósito de la intención de regular la imprescriptibilidad para algunos delitos en la constitución del Perú, publicado en Gaceta Penal \& procesal penal, tomo 89/ noviembre de 2016, pp. 313 a 330

3 García Belaunde, D. (2016). Las constituciones del Perú. Tercera edición revisada, corregida y aumentada. Lima, Perú: Fondo Editorial de Jurado Nacional de Elecciones. Así como la publicación de Las Constituciones del Perú, editado por el Tribunal Constitucional, el Centro de Estudios Constitucionales y el Ministerio de Justicia y Derechos Humanos y el Centro de Estudios en Justicia y Derechos Humanos, como parte de la Biblioteca Juridica del Bicentenario 1821-2021 de la colección Constituciones y Debates Constituyentes 1. Aunque el primer autor que hizo esta tarea fue José Pareja Paz-Soldán en su obra Las Constituciones del Perú del año .... aunque ya en otras áreas se había propuesto su regulación como lo afirma José Pareja Paz-Soldán citado por Carlos Ramos (2017) al referirse al art. 41 de la Constitución de $1920^{4}$, igualmente lo reguló la Constitución de $1933^{5}$, la Constitución de $1979^{6}$ y la vigente Constitución de $1993^{7}$.

\section{ALGUNOS FUNDAMENTOS DE LA IMPRESCRIPTIBILIDAD}

La imprescriptibilidad ha tenido diversos fundamentos a lo largo de la historia, esto ya se ha tratado en otra investigación, sin embargo, hay hubo algunos autores que postularon la idea de vincular el tema de la imprescriptibilidad con el perdón desde la filosofía francesa, luego de la Segunda Guerra Mundial, así Jankelévitch y Derrida, por mencionar solo dos, aunque hay muchos más ${ }^{8}$, con presupuestos y consecuencias diferentes)

Jankelévitch (1986) luego de explicar la naturaleza del delito de genocidio contra los judíos por parte de los alemanes señaló que

cuando un acto niega la esencia del hombre en tanto que hombre, la prescripción tendiente a absolverlo en nombre de la moral contradice ella misma a la moral. ¿No es contradictorio y hasta absurdo invocar aquí el perdón? Olvidar este crimen gigantesco contra la humanidad sería un nuevo crimen contra el género humano. (Página 27)

Sobre el tiempo como fundamento de la prescripción Jankelévitch (1986) señaló:

El tiempo que lo limita todo, el tiempo que desgasta la tristeza como erosiona las montañas, el tiempo que favorece el perdón y el olvido, el tiempo que consuela,

4 Art. 41.- "Los bienes de propiedad del Estado, de instituciones públicas y de comunidades indigenas son imprescriptibles (...)".

5 En esta constitución se reguló el Art. 209 señaló "La propiedad de las comunidades indigenas es imprescriptible (...)".

6 En esta constitución se reguló el Art. 163.- "Las tierras de las Comunidades Campesinas y Nativas son inembargables (...)".

7 En esta constitución se reguló el Art. 89.- "La propiedad de sus tierras es imprescriptible (...)".

8 Por ejemplo, el profesor español Cerrada Moreno (2018) señala que "la existencia de delitos imprescriptibles, que rompe la regla general de la prescripción, pone de manifiesto que no existe un fundamento único para que "el delito" como concepto prescriba, si no que "cada delito" de los tipificados en el Código podrá prescribir (o no). Y no existe razón para afirmar que, respecto de los que pueden prescribir, tal posibilidad responda a un único fundamento" (Cerrada Moreno, M (2018), p. 219). 
el tiempo liquidador y cicatrizador, no atenúa en nada la colosal hecatombe: al contrario, no cesa de reavivar su horror. El voto del Parlamento francés enuncia con todo derecho un principio $y$, de alguna manera, una imposibilidad a priori: los crímenes contra la humanidad son imprescriptibles, o sea no pueden ser prescriptos; el tiempo no les hace mella. No se trata de que haga falta una prórroga de diez años para castigar a los últimos culpables. Es en general incomprensible que el tiempo, proceso natural sin valor normativo, pueda ejercer una acción atenuante sobre el insostenible horror de Auschwitz. (Páginas 27 y 28) ${ }^{9}$

Por su parte Derrida (2015) señaló al distinguir entre las formas de perdón puro o incondicional y el impuro o condicional,

entre el perdón puro o incondicional, y esas formas próximas y heterogéneas de remisión, heterogéneas entre ellas, heterogéneas con respecto al perdón y que denominados la excusa, el arrepentimiento (regret), la prescripción, la amnistía, etc., tanto formas de perdón condicional (y por tanto, impuro), y en ocasiones formas jurídico políticas", agregando más adelante el autor que "Incluso si "imprescriptible" no quiere decir "imperdonables" la contaminación de estos dos órdenes no será un accidente reductible. (Páginas 61 y 62).

De lo expresado por ambos autores se desprende que lo prescriptible y lo imprescriptible no depende únicamente del transcurso del tiempo, sino en algunos casos del perdón, aunque a veces, como lo señaló Derrida (2015), lo imprescriptible no significó lo imperdonable.

Por lo tanto, tratándose de los delitos contra la administración pública, organizada o individual, pero considerada grave pueda olvidarse y por ende perdonarse y luego permitirse su prescripción para todos aquellos casos de corrupción (en sentido amplio) más graves para el país. Entonces, solo la aplicación de la reforma penal constitucional implementada o regulada en el Código penal

9 Jankelévitch pone como ejemplo a Heinz Lammerding, quien fue comandante de la división "Das Reich" que en 1994 como represalia de los ataques aliados ordenó la masacre de civiles en Tulle y Oradour (el 10 de junio de 1944), con 642 civiles asesinados. Asi mismo, los Malogré-nous (a nuestro pesar), que participaron en la muerte de sus compatriotas franceses, fueron condenados y luego amnistiados, y recién en 1994 hubo una reconciliación. de 1991 demostrará o no, qué tan relevante fue en un futuro inmediato, más aún en un contexto donde la corrupción ad portas del bicentenario de fundación de la república, resulta ser un problema estructural y no coyuntural.

\section{OBSERVACIONES A LA REFORMA O ENMIENDA PENAL CONSTITUCIONAL}

Los académicos no suelen ser personas ajenas a la realidad, sino más bien a partir de ella en base a la observación, las experiencias y el conocimiento científico, tratan de ser los intérpretes del quehacer humano. Es así que ante la coyuntura política los congresistas, los jueces, los fiscales, los abogados, los periodistas, los demás profesionales (ingenieros, economistas, contadores, y otros) y la sociedad en general (no solo la llamada "sociedad civil", empresarios, gremios sindicales, etc.), se han pronunciado sobre la imprescriptibilidad penal para los delitos de corrupción pública, unos con el afán de señalar que se trata de un problema meramente coyuntural, otros haciendo hincapié en que se trata de un problema estructural, para lo cual, a su manera, cada uno de estos sectores vienen proponiendo algunas alternativas de solución, algunas más tibias que otras, como a continuación se señalan a través de las siguientes observaciones:

1. La imprescriptibilidad penal es muy criticada desde la perspectiva de la teoría de la pena, y solo se le acepta excepcionalmente ${ }^{10}$.

10 En materia de imprescriptibilidad señala Omar Huertas Díaz "estos crimenes son imprescriptibles porque son incompatibles con el olvido. La prescripción no puede ser entendida como un acto de voluntad igual a la amnistia ol alvido del tiempo, que garantiza la impunidad de los crimenes después de un determinado plazo transcurrido desde los hechos (que impide la persecución penal, prescripción de acción pública) o desde la condena (prescripción de la pena, que no será ejecutada). La impunidad cuando bloquea cualquier procedimiento, impide la formación de la memoria, la cual no tiene como función esencial regodearse en el pasado, sino alimentar el presente y preparar el en el pasado, sino alimentar el presente y preparar el
futuro" (En Revista Pensamiento Jurídico, $\mathrm{N}^{\circ} 37$, MayoAgosto, Bogotá-Colombia, 2013, p. 25, artículo titulado el debate de la imprescriptibilidad de los delitos de lesa humanidad en Colombia: Análisis desde la perspectiva de los derechos humanos). Agrega el autor que "por lo tanto, se puede concluir que la imprescriptibilidad de los crimenes de lesa humanidad forma parte del principio de jurisdicción universal. Además, se ha evidenciado que el jurisdicción universal. Además, se ha evidenciado que el Estado para perseguir, a través de su propia jurisdicción penal, a los responsables, incluso aunque no exista vinculo directo entre el hecho delictivo y el ordenamiento interno. Ello, sobre la base de la naturaleza del principio de jurisdicción universal, para lo cual se ha creado un régimen jurídico ad hoc idóneo que excluya la aplicación, no solo de la prescripción, sino de cualquier institución que pudiera obstaculizar su efectiva represión y castigo" (27) 
2. La tesis mayoritaria aceptada en materia penal es el enfoque de naturaleza eminentemente sustantivo.

3. La fórmula aprobada por el Congreso de la República resulta contradictoria con lo que se ha venido predicando como discurso justificado, pues por un lado se restringe los alcances de la prescripción penal (tanto para la acción penal, como para la ejecución de la pena) y por otro, los amplía.

\section{Por el lado de la restricción.}

No se menciona la duplicidad del plazo de prescripción, ni tampoco la imprescriptibilidad para aquellos funcionarios o servidores públicos que integran una organización criminal, o es que acaso nos preguntamos ¿los funcionarios o servidores públicos no pueden formar parte de una organización criminal?

El art. 80 in fine del CP de 1991 señala que "en caso de delitos cometidos por funcionarios y servidores públicos contra el Patrimonio del Estado o de organismos sostenidos por este, o cometidos como integrante de organizaciones criminales, el plazo de prescripción se duplica".

Como se aprecia, lo subrayado no aparece en la propuesta formulada, por ello se generaría una primera hipótesis, acaso esto significaría una consecuencia gravísima para el sistema penal, pues se habría despenalizado el supuesto de la duplicidad del plazo de prescripción, para todos aquellos funcionarios que forman parte de una organización criminal, o se tendría como una segunda hipótesis que sí se va a mantener la fórmula, a pesar que el texto constitucional no lo contiene y a pesar de las consecuencias que originen estas.

Si se asume la primera hipótesis, es decir se deroga dicho supuesto ¿qué pasaría, por ejemplo, si un funcionario público, que forma parte de una organización criminal, que comete un delito de colusión simple (art. 384 primer párrafo)? El plazo de prescripción será el plazo ordinario o extraordinario sin la duplicidad, es decir el caso resulta prescriptible, pero sin la duplicidad.

Por tanto, esto amerita una precisión, vía una corrección inmediata, por parte de todos aquellos congresistas que han aplaudido la propuesta aprobada por el Congreso de la República desde la perspectiva de la lucha contra la corrupción.
En síntesis, los 109 congresistas serán responsables de la propuesta aprobada en primera votación, si no se regula la imprescriptibilidad en el CP de 1991, por ello esperamos que ahora se corrija tamaña dejadez u omisión ${ }^{11}$.

\section{Por el lado de la ampliación de los supuestos.}

Resulta necesario precisar que la propuesta legislativa aprobada que incorpora la imprescriptibilidad penal, contempla los supuestos de corrupción realizados por personas particulares, aunque ahora habrá que preguntarse si el plazo de prescripción para particulares no solo se duplica, sino también resulta que para los casos de delitos graves el supuesto sería imprescriptible, con lo cual se abandona los criterios fijados por la Corte Suprema en el acuerdo plenario que estableció la consecuencia jurídica de rebajar los plazos de prescripción para todos los supuestos en los que participen los extraneus en los delitos contra la administración pública considerados de mayor gravedad, lo cual hay que definir.

Otra particularidad se presenta en los casos de prescripción de la ejecución de la pena, que la reforma no contempló expresamente, por ende, cabe preguntarse $i$ si en estos casos se va o no a aplicar la consecuencia jurídica de la imprescriptibilidad?

La respuesta cae por su propio peso, pues la regla de la imprescriptibilidad penal al amparo de las exigencias del principio de legalidad y tratándose de una causal de extinción podría aplicarse por interpretación analógica de manera favorable a todos los condenados, sin embargo al tratarse de una regla de prohibición de la prescripción, esta no alcanzaría a los casos de prescripción de la ejecución de la pena, por tanto también debería corregirse de inmediato esta gravísima omisión.

\section{EL TRATAMIENTO DE LA REFORMA APROBADA}

El texto introducido en la reforma constitucional al introducir la imprescriptibilidad en

11 No hay que olvidar que la incorporación de la imprescriptibilidad en el articulo 41 de la Constitución de 1993 cerró la posibilidad de aplicarla a otros delitos, respecto a lo cual ya nos hemos pronunciado anteriormente respecto a lo cual ya nos hemos pronunciado anteriormente
en otro artículo. Sin embargo, seria necesario corregir la forma de la imprescriptibilidad para considerar el supuesto de la organización criminal. 
materia penal tuvo, coincidentemente, como protagonistas a los congresistas de la bancada de la misma la línea política e ideológica de los congresistas constituyentes (Congreso Constituyente Democrático) ${ }^{12}$ que originalmente propusieron el artículo 41 de Constitución de 1993, al regular por primera vez la duplicidad del plazo de la prescripción penal.

El texto de la enmienda constitucional, aprobado por ley $\mathrm{N}^{\circ} 30650$, cuyo texto incorporó al art. 41 in fine:

El plazo de prescripción de la acción penal se duplica en caso de los delitos cometidos contra la Administración Pública o el patrimonio del Estado, tanto para los funcionarios o servidores públicos como para los particulares. La acción penal es imprescriptible en los supuestos más graves, conforme al principio de legalidad.

Al respecto se debe señalar que esta ley penal constitucional no es de aplicación inmediata o directa, sino que requiere de una ley derivada o de desarrollo, tan igual que su predecesora, es decir el caso de la duplicidad en el plazo de la prescripción de la acción penal regulada en la primera parte del último párrafo del art. 41 de la Constitución de 1993, desarrollada mediante la ley $\mathrm{N}^{\circ} 26314^{13}$

Sin embargo, se debe señalar que cualquier interpretación debe regirse por el criterio de interpretación de "conformidad con la Constitución”, así Larenz (1980) señaló que:

Como las normas constitucionales preceden en rango a todas las demás normas jurídicas, una disposición del simple Derecho legal, que esté en contradicción con un principio constitucional, es inválida. Además de ella, sólo el Tribunal Constitucional Federal puede decidir si una disposición del Derecho posconstitucional contradice la Constitución. (Página 338)

12 El texto original del art. 41 de la Constitución de 1993 se aprobó por el CCD (Congreso Constituyente Democrático) por parte de los congresistas pertenecientes a la alianza de los partidos politicos Cambio 90 y Nueva Mayoria (C90-NM) que tuvieron el control del parlamento, asi como la actual reforma constitucional que propuso la modificatoria de artículo 41 in fine, por el partido político rebautizado y de la misma línea política que su predecesor, nos referimos a Fuerza Popular.

13 Texto promulgado el 26 de mayo de 1994, y sobre este particular véase la tesis de magister titulada "La prescripción penal en el Perú (A veinte años de vigencia del código penal de 1991)" en la UNMSM, p. 89 tomo I, y la nota a pie de página $\mathrm{N}^{\circ} 192$.
En la teoría general del derecho Riccardo Guastini (2016) clasifica a las normas a partir del criterio de la posición que ocupan en la estructura del ordenamiento jurídico en originarias y derivadas, señalando que "son originarias -independientes, supremas, "soberanas"- las normas cuya pertenencia al ordenamiento no depende de la (previa) existencia de otras normas. Tales son las normas constitucionales o si se quiere, las normas de "primera" Constitución (en el caso de una secuencia de Constituciones cada una de las cuales sea jurídicamente fundada sobre la precedente)" (Guastini 2016, Página 620).

El mismo autor define a las normas derivadas "-dependientes- todas las normas remanentes: todas aquellas, esto es, cuya existencia reposa -dinámica o sistemáticamente, como veremossobre la previa existencia de otras normas, porque (a) han sido emanadas de un sujeto investido de autoridad normativa por una norma preexistente, o porque (b) derivan lógicamente (o pseudo lógicamente) de normas preexistentes" (Guastini 2016, Página 620 y 621).

Si por principio se entiende como lo hace Ricardo Guastini (2007) "toda norma que presenta las características de ser normas fundamentales $y$ normas estructuralmente indeterminadas" (Página 74 y 75).

Para los fines de esta investigación interesan las normas estructuralmente indeterminadas que "no se refieren a la posición de las normas en el sistema jurídico, sino al contenido mismo de las normas y/o a su estructura normativa" (Guastini 2007, Página 75).

Además, dentro de su construcción teórica el mismo Ricardo Guastini (2007) diferencia dos formas de indeterminación, el carácter derrotable y el carácter genérico, los mismos a los que se referirá a continuación.

Por un lado, "una norma es "inderrotable" -y entonces es una "regla"-cuando establece de manera completa, exhaustivo, tanto los hechos en presencia de los cuales se produce la consecuencia jurídica que la propia norma establece, como las excepciones en presunción de las cuales la consecuencia no se produce. Una norma, por el contrario, es "derrotable" (defeasible)- y entonces es un "principio"cuando no establece exhaustivamente los hechos condicionantes, o bien no enumera 
todas excepciones" (Guastini 2007, Página 75 y 76$)^{14}$.

De allí que el mismo Guastini (2007) precisa:

La derrotabilidad no es una propiedad objetiva de las normas (de ciertas normas, y no de otros): es el producto de la interpretación. En otras palabras, es la interpretación, y solo la interpretación, la que a veces mediante la técnica de la "disociación" introduce en las normas algunas excepciones implícitas. (Página 76)

Por otro lado, Ricardo Guastini (2007, Página 76) considera que "una norma "precisa"-y por tanto una "regla"-es una norma inmediatamente susceptible de aplicación a casos concretos: una norma que puede utilizarse como premisa mayor en el silogismo jurisdiccional " $\mathrm{Si}$ F, entonces G; es el caso que F, luego G", o bien "Todos los ladrones deben ser castigados; Fulano es un ladrón, luego Fulano debe ser castigado"). Una norma "genérica"-y entonces un "principio"-en cambio es una norma que: a) por un lado, exige la formulación de otras normas- que la "concreticen", la "actualicen" o le den "ejecución"-sin las cuales no sería apta para resolver casos concretos; pero, b) por otro lado, puede actualizarse, ejecutarse o concretizarse en formas muy diferentes y alternativas ${ }^{15}$.

Sin embargo, hay que dejar sentado que (en el Perú) se puede distinguir entre la regla y el

\footnotetext{
14 Como ejemplo de derrotabilidad este autor señala utilizando la Constitución italiana: "el principio de igualdad (art. 3, ap. 1) prohíbe al legislador hacer discriminaciones entre los ciudadanos a partir del sexo, la raza, la lengua, la religión, las la religion, las opiniones politi personales y sociales. Pues bien, según la jurisprudencia del Tribunal constitucional: a) por un lado, una ley bien puede ser inconstitucional si distingue entre los ciudadanos por otro criterio, no incluido en la lista de los criterios de discriminación expresamente prohibidos por la constitución, por ejemplo, por la edad (hecho condicional implicito), ya que el legislador debe distinguir entre casos implicito), ya que el legislador deb

15 Este autor utiliza como ejemplo el caso de "una la norma constitucional establece que el jefe del estado sea un órgano electivo. Pues bien: en primer lugar, una norma como ésta no es aplicable en ausencia de otras normas que determinen las modalidades de elección del jefe del estado; pero, en segundo lugar, las modalidades de elección del jefe del estado pueden ser de lo más variadas (sin que se viole el principio). Otro ejemplo: consideremos una norma constitucional que otorgue un "derecho social", como el derecho al trabajo o el derecho a la salud; se trata de una norma programática o teleológica, que le recomienda al legislador que persiga un fin determinado; pues bien, una norma como esta exige otras normas (legislativas y/o reglamentarias) que concreticen el derecho otorgado, pero evidentemente el derecho en cuestión puede ser concretizado en muchos modos diversos" (Guastini, 2007, pp. 75-77).
}

principio, aunque en materia de prescripción se tendría la postura que la regla es la prescripción penal y la excepción la imprescriptibilidad penal, aunque a partir de su estructura se señalaría que se trata en sí de una regla de prohibición.

No se considera el caso de la imprescriptibilidad como principio del ius cogens para los casos, por ejemplo, de delitos de lesa humanidad, pues la reforma constitucional reconoce el modelo de la prescripción, de allí que la justificación de la prohibición de la prescripción deviene de criterios de política criminal específicamente.

También el Tribunal Constitucional se manifestó al establecer que las leyes de desarrollo son:

La Ley de desarrollo de la Constitución, expedida por el Congreso de la República, y así denominada por la Octava Disposición Final y Transitoria de la Constitución, que no constituye una categoría especial de la forma normativa ley, sino que comprende tanto a la ley ordinaria como a la ley orgánica. Al respecto, el Tribunal Constitucional ha establecido:

Con la expresión "Ley de desarrollo constitucional", la Octava Disposición Final y Transitoria de la Constitución no ha creado una categoría normativa especial entre las fuentes que tienen el rango de ley. Tal expresión no alude a una categoría unitaria de fuentes, sino a una diversidad de ellas, que tienen como elemento común constituir un desarrollo de las materias previstas en diversos preceptos constitucionales, cuya reglamentación la Norma Suprema ha encargado al legislador. Forman parte de su contenido "natural" las denominadas leyes orgánicas, en tanto que mediante ellas se regula la estructura y funcionamiento de las entidades del Estado previstas en la Constitución, y de otras materias cuya regulación por ley orgánica está establecida en la Constitución; así como las leyes ordinarias como las que demandan los artículos $7^{\circ}$ y $27^{\circ}$ de la Constitución, por poner dos ejemplos, a las que se les ha encomendado la tarea de precisar los alcances de determinados derechos o instituciones constitucionalmente previstas. 
Ello significa, desde luego, que la condición de "leyes de desarrollo constitucional" no se agotan en aquellas cuyas materias se ha previsto en la Octava Disposición Final y Transitoria de la Constitución, esto es, a lo que allí se alude como leyes en materia de descentralización y las relativas a los mecanismos y al proceso para eliminar progresivamente los monopolios legales otorgados en las concesiones y licencias de servicios públicos; dado que sobre estas últimas, la Constitución sólo ha exigido del legislador cierto grado de diligencia ("prioridad") en su dictado.[38] (Tribunal Constitucional, Exp. N 047-2004-AI-TC)

Desde la perspectiva de la técnica legislativa se ha señalado que las leyes deben ser completas, así lo señala la profesora Piedad GarcíaEscudero (2011):

\subsubsection{LA LEY DEBE SER COMPLETA}

La ley debe contener la regulación completa de su objeto material, enviándose en la medida de lo posible la dispersión normativa, esto es, la regulación parcial de una misma materia en varias leyes distintas, pues esto complica el ordenamiento y dificulta el conocimiento y localización de la normativa aplicable.

La confusión no deriva sólo del número de leyes, sino también de que éstas son fragmentarias, sectoriales, estratificadas, provocando lo que V. Italia califica de dodecafonía jurídica, que sitúa al intérprete ante un mosaico impreciso frente a la solemne arquitectura de los códigos.

Como señalan las Directrices de Técnica Normativa, en la medida de lo posible, en una misma disposición deberá regularse un único objeto, todo el contenido del objeto $\mathrm{y}$, si procede, los aspectos que guarden directa relación con él.

No obstante, el Tribunal Constitucional considera que la normación completa de una materia en una ley o por partes en varias leyes forma parte del ámbito de decisión del legislador, «salvo aquello casos en que la Constitución establece la unidad de legislación en una misma materia o para un conjunto de problemas o soluciones enlazados y próximos entre sí, sin perjuicio de que una vez establecida esta legislación pueda modificarse parcialmente», como ocurre en el caso de la ley electoral (STC 72/1984, F. 5).

En la sentencia 5/1982 (F. 1) el Tribunal señala que la «la interdicción de una normación parcial de una determinada materia implicaría, sin duda, una norma excepcional que sólo puede estimarse existente cuando explícitamente ha sido establecida»

No obstante, como señala Sainz Moreno, la regulación fragmentada de una materia en distintas normas sólo está justificada cuando lo exige la distribución de las competencias normativas (entre Unión Europea y Estados miembros, entre el Estado y las Comunidades Autónomas), el principio de reserva de leyes o la Constitución cuando obliga a incluir ciertas regulaciones en normas asignadas nominativamente (por ejemplo, artículos 70, 104, 107 y 122 CE) (Página 96).

Por todo lo manifestado se establece indudablemente que esta reforma constitucional adolece de muchos defectos de técnica legislativa, los mismo que se repetirán en la correspondiente ley de desarrollo si es que no se producen las correcciones apropiadas.

\section{LAS ANTINOMIAS O INCOMPATIBILIDADES ENTRE LA PRIMERA PARTE DEL ÚLTIMO PÁRRAFO Y LA SEGUNDA PARTE DEL ÚLTIMO PÁRRAFO DEL ART. 41 DE LA CONSTITUCIÓN DE 1993.}

Las antinomias o incompatibilidades entre las reglas que regulan la prescripción de la acción penal y la prohibición de la prescripción o imprescriptibilidad de la acción penal, no se aprecia a nivel de la regla penal constitucional, sino a nivel de la regla penal legal, por ello se requiere de una ley de desarrollo.

A partir de la consistencia o coherencia de un cuerpo jurídico que "consiste en la exclusión de su seno de las contradicciones entre normas jurídicas" (Capella 1999, página 108) o antinomias jurídicas, y si se trata del 
sistema penal, entonces se definirán a las antinomias jurídico penales como la ausencia de contradicciones entre las normas penales.

Lo compatible radica en que los presupuestos de la prescripción y de la imprescriptibilidad están dirigidos a los mismos sujetos activos, es decir para los funcionarios y servidores públicos, como para los particulares, siempre y cuando se afecte al mismo bien jurídico genérico, esto es la correcta administración pública, o al objeto material del tipo penal, esto es el patrimonio del Estado o de los organismos sostenidos por el Estado.

Tal vez uno de los inconvenientes de la regla penal legal fue el no mencionar expresamente el caso en el que el sujeto activo resulta ser un particular, esta omisión del legislador luego sirvió para que la Corte Suprema determinó vía el acuerdo plenario ... que los plazos de prescripción de la acción penal para los partícipes extraneus serían menores.

Otro de los aspectos que no se reguló en la ley de desarrollo fue la mención al bien jurídico, pues la norma no precisó los delitos cometidos contra la administración pública, sino solo el objeto material como lo es el patrimonio del Estado o de los organismos sostenidos por el Estado.

Finalmente, se debería precisar la incompatibilidad del supuesto de delitos cometidos como integrante de organizaciones criminales, para lo cual se tiene que recurrir a la ley $\mathrm{N}^{\circ} 30077$, especialmente para el caso del delito de lavado de activos, entre otros para determinar la duplicidad del plazo de prescripción de la acción penal. Por ello, se hace necesario hacer algunas precisiones.

\section{El plano de la duplicidad}

En un primer plano nunca quedó claro los límites y márgenes del supuesto establecido en la ley penal constitucional que reguló el art. 41 in fine, "el plazo de prescripción se duplica en caso de delitos cometidos contra el patrimonio del Estado".

En esos momentos, los congresistas establecieron la regulación de desarrollo y a la vez de remisión, del supuesto de la regla constitucional mediante la ley $\mathrm{N}^{\circ}$ 26314, la cual incorporó el último párrafo al art. 80 in fine al Código Penal de 1991, que dispuso "en caso de delitos cometidos por funcionarios y servidores públicos contra el patrimonio del Estado o de organismos sostenidos por éste".

El supuesto de desarrollo consignó, en primer lugar, la referencia a los sujetos activos del delito de forma alternativa, el primero el funcionario público y el segundo el servidor público. En segundo lugar, en torno al objeto material, se estableció dos supuestos alternativos, uno referido al patrimonio del Estado y el otro al patrimonio de organismos sostenidos por el Estado.

Sin embargo, el legislador cayó en una incoherencia al incrementar un nuevo supuesto que no tenía relación con la disposición criminal, como lo es el señalar que si se comete un delito en la modalidad de criminalidad organizada ${ }^{16}$, el plazo de la prescripción se duplica.

De ello se extraen dos opciones interpretativas. La primera que el legislador no respetó la regla penal constitucional, entonces dicha reforma devendría en inconstitucional.

La segunda, que la duplicidad del plazo de la prescripción no requería una regla penal constitucional, por lo cual si bien es cierto el poder constituyente la estableció, empero no se requería del mismo, pues el legislador la podía regular, aunque cabe recordar que considerando los antecedentes de dicha institución, la duplicidad del plazo de la prescripción de la acción penal nunca se reguló a nivel de regla penal legal o por ley (ni los anteproyectos y proyectos de ley, ni los anteriores códigos penales regularon esta propuesta).

\section{El plano de la prohibición de la prescripción}

Empero, ahora si va a tener que tomar postura el legislador, pues la reforma constitucional del art. 41 de la Constitución de 1993 (ley Nº

16 Zúñiga Rodríguez, L. (2009), p. 269 y ss., en donde la autora expresa que la organización criminal tiene "tres elementos que consideramos indispensables: la organización, la finalidad delictiva y la comisión de delitos graves. Ahora, bien, categorizar estos elementos de acuerdo a los conceptos penales distinguiendo los elementos objetivos de los subjetivos no es posible, como ya se ha puesto de manifiesto. Señalaré los elementos básicos que ha de tener el injusto de organización criminal para ser considerado como tal y, por tanto, deben estar descritos en toda norma penal", como la destructurc de delitos graves, pactum sceleris o acuerdo societario, el programa criminal, y los miembros de la organización, aunque con la precisión de que los tres primeros son los requisitos básicos del injusto penal. 
30650) dispone el régimen para la duplicidad del plazo de la prescripción y el nuevo supuesto de la prohibición de la prescripción denominado imprescriptibilidad, para los delitos cometidos contra la administración pública o el patrimonio del Estado, tanto para funcionarios como servidores públicos o particulares en los supuestos más graves (el mismo que se desarrolla abajo), en los demás supuestos de duplicará el plazo de prescripción.

\section{La mención al principio de legalidad}

Otro aspecto que se observa es que la referencia constitucional debió hacerse a la ley y no al principio de legalidad, pues la determinación de establecer en el supuesto de un determinado tipo penal o sus modalidades o sus supuestos agravados requiere de una valoración a partir de la referencia a la lesión o puesta en peligro del bien jurídico y su relevancia (principio de lesividad), al principio de proporcionalidad, al principio de igualdad, entre otros. No es solo señalar un tipo penal y excluir otro, se requiere de una apreciación por parte del legislador tomando en consideración los principios del derecho penal a fin de evitar la arbitrariedad o la sobre criminalización.

\section{¿QUÉ IMPLICA LA FÓRMULA "SUPUESTOS MÁS GRAVES"?}

La fórmula "supuestos más graves" establecida en la regla penal constitucional abordada desde el plano legal en materia penal no tienen referencia alguna, pues ni el Código Penal de 1991 ni las leyes especiales penales contemplan fórmula alguna para referirse a delitos graves, sean estas de la parte general o la parte especial, o ambas. Pero también se ha utilizado la fórmula en la legislación procesal penal, así como en la ejecución penal.

En la doctrina es discutida la mención al término delito grave, así la profesora Laura Zúñiga (2009) señala al referirse a uno de los presupuestos de la organización criminal señala:

La gravedad de los delitos es un término valorativo difícil de consensuar a nivel del Derecho Comparado", agregando que "la doctrina se pregunta si es más recomendable un catálogo cerrado de delitos graves o una referencia genérica a la gravedad de la pena. Un catálogo cerrado de delitos tiene la ventaja de incorporar necesariamente los delitos que se consideran «tradicionales» de la criminalidad organizada: tráfico de drogas, blanqueo de capitales, tráfico de personas, etc.; pero tiene la desventaja de cerrar las puertas a futuras manifestaciones de la criminalidad organizada con dañosidad social que se dedique a la comisión de delitos no contemplados en el catálogo. Si hemos establecido la lesividad del injusto de organización criminal en relación al bien jurídico del delito-fin, parece importante delimitarlos. La gravedad de los delitos en un primer término, pero un segundo término es definir claramente qué se entiende por gravedad. Considero que la determinación de un catálogo cerrado de delitos es más conforme con el principio de taxatividad que se pretende salvaguardar en este injusto. Establecer numerus clausus, tiene la ventaja de obligar al legislador a pensar en cuáles son los delitos que se pueden cometer más corrientemente por organizaciones criminales y que pueden producir gran dañosidad social. Aunque la realidad de la criminalidad organizada siempre va por delante de la ley, sería un precio a pagar. (Página 265)

A continuación, se desarrollarán cada uno de los enfoques mencionados.

\section{La perspectiva procesal penal}

Desde la perspectiva procesal, en el art. 24 del Código Procesal Penal se alude a los delitos graves y su relación con la trascendencia nacional. Asi se tiene que:

Artículo $24^{\circ}$. Delitos graves y de trascendencia nacional.

Los delitos especialmente graves, o los que produzcan repercusión nacional cuyos efectos superen el ámbito de un Distrito Judicial, o los cometidos por organizaciones delictivas, que la Ley establezca, podrán ser conocidos por determinados jueces de la jurisdicción penal ordinaria, bajo un sistema específico de organización territorial y funcional, que determine el Órgano de Gobierno del Poder Judicial. 
Los delitos de tráfico ilícito de drogas y lavado de activos; $y$, los delitos de secuestro y extorsión que afecten a funcionarios del estado, podrán ser de conocimiento de los jueces de la capital de la República, con prescindencia del lugar en el que hayan sido perpetrados.

Aquí hay que distinguir varias categorías de distinta naturaleza que se equiparan, por un lado, se habla de delitos especialmente graves, luego delitos que produzcan repercusión nacional cuyos efectos superen el ámbito de un Distrito Judicial, también de delitos cometidos por organizaciones delictivas, y estas categorías a la vez se entremezclan con delitos específicos como el tráfico ilícito de drogas, el lavado de activos, el secuestro y la extorsión que afecten a funcionarios del estado.

Bajo estas circunstancias entonces, lo que queda claro es que tampoco la perspectiva procesal resulta satisfactoria para poder justificar algún abono para interpretar o dotar de contenido al art. 41 de la Constitución de 1993.

\section{La perspectiva de la ejecución penal}

En el campo de la ejecución penal, también se aprecia la utilización de esta fórmula al referirse a los requisitos de procedencia para la obtención de los beneficios penitenciario que permiten la excarcelación, tales como la semilibertad y la liberación condicional.

Cuando se produce la condena de una persona por un determinado delito hay que precisar en primer lugar varios estadios, uno si la condena de pena privativa de la libertad es efectiva o no, otro si la condena efectiva es por un corto tiempo o por un largo tiempo, otro es el caso de si la condena es por un delito muy grave o de un delito grava, entre otras variantes, como por ejemplo la reincidencia.

De allí que resulta pertinente traer a colación la advertencia planteada desde la teoría general del derecho, de tener cuidado con caer bajo los alcances de una norma perversa, es decir que no se cumple o que se cumple de vez en cuando, en la concesión de los beneficios penitenciarios de semilibertad y liberación condicional.

Por ejemplo, si se considera el caso de los delitos muy graves y graves, tenemos que para los muy graves se excluyen los beneficios penitenciarios de semilibertad y liberación condicional $^{17,18}$ y para los graves sí hay beneficios penitenciarios con un régimen especial o común, pero hay que aclarar que no todos los delitos considerados muy graves (desde la perspectiva de la pena) tienen la prohibición de los beneficios penitenciarios mencionados.

Por ello, no sería coherente, sino contingente tomar en cuenta la perspectiva de la ejecución penal, pues sus resultados serían erráticos si se aplicara para los supuestos del art. 41 in fine de la Constitución.

\section{La perspectiva del derecho penal internacional ${ }^{19}$ y de delitos transnacionales}

Si se partiera desde la perspectiva del derecho penal internacional, habría que señalar que todo delito o crimen regulado en el Estatuto de la Corte Penal Internacional establece en su regulación las acciones penales relevantes para la comunidad internacional producto del consenso, donde la proporción de las penas, la técnica legislativa de tipos básicos y agravados pasan a un segundo plano, por ende, este plano es eminentemente cualitativo.

De allí que no sería recomendable asumir un modelo de esta naturaleza salvo que se considere todas las conductas prohibidas cualitativamente, pero como no se regula en dicho Estatuto

17 Conforme al art. 1 de la Ley $N^{\circ} 30609$, publicada el 19 de julio de 2017: "Tampoco son procedentes para aquellos internos que se encuentran sentenciados por la comisión de los delitos previstos en los artículos 107, 108, 108-A, 108-B, 121-B, 152, 153, 153-A, 170 al 174, 176-A, 177, 189, 200, 279-A, 297, 317, 317-A, 317-B, 319, 320, 321, 322, 323, primer, segundo y tercer párrafo del 387, 389, 393, 393-A 394, 395, 396, 397, 397-A, 398, 399, 400 y 401".

18 También se tiene la modificación del artículo 50 del Código de Ejecución Penal, por el artículo 2 del Decreto Legislativo $\mathrm{N}^{\circ}$ 1296, publicado el 30 diciembre 2016, cuyo texto es el siguiente: "No son procedentes los beneficios penitenciarios de semi-libertad y liberación condicional para aquellos internos que hayan cometido delitos vinculados al crimen organizado conforme a la Ley 30077 Ley Contra el Crimen organizado conf
Organizado"

19 Hay que dejar en claro la distinción entre el objeto del Derecho penal internacional, es decir los crimenes internacionales con los delitos transnacionales, en el primer caso se refiere a "un núcleo bastante reducido de delitos que, por sus características, afectan a la comunidad internacional en su conjunto" (Gil Gil, A. (2016), p. 43), este internacional en su conjunto" (Gil Gil, A. (2016), p. 43), este o Estatuto de Roma, en cambio en el segundo caso "se distingue de otros delitos que son a menudo objeto de regulación mediante instrumentos internacionales que pretenden la armonización de las legislaciones internas y la cooperación interestatal y la cooperación interestatal en la lucha contra los mismos" (Gil Gil, A. (2016), p. 45), este sería el caso de la Convención Interamericana Contra la Corrupción. 
entonces habría que revisar la Convención Interamericana Contra la Corrupción. En cambio, si se parte de dicha Convención la solución se encontraría en proponer todas las accione penales relevantes que se regulan en los artículos VI (referido a los actos de

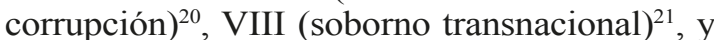
IX (enriquecimiento ilícito) $)^{22}$.

20 La Convención señala en su artículo VI los actos de corrupción:

1. La presente Convención es aplicable a los siguientes actos de corrupción:

a. El requerimiento o la aceptación, directa indirectamente, por un funcionario público o una persona que ejerza funciones públicas, de cualquier objeto de valor pecuniario u otros beneficios como objeto de valor pecuniario u otros beneficios como
dádivas, favores, promesas o ventajas para sí mismo o para otra persona o entidad a cambio de la realización $\mathrm{u}$ omisión de cualquier acto en el ejercicio de sus funciones públicas;

b. El ofrecimiento o el otorgamiento, directa indirectamente, a un funcionario público o a una persona que ejerza funciones públicas, de cualquier objeto de valor pecuniario $\mathrm{u}$ otros beneficios como dádivas, favores, promesas o ventajas para ese funcionario público o para otra persona o entidad a cambio de la realización u omisión de cualquier acto en el ejercicio de sus funciones públicas;

c. La realización por parte de un funcionario público 0 una persona que ejerza funciones públicas de cualquier acto u omisión en el ejercicio de sus funciones, con el fin de obtener ilicitamente beneficios para sí mismo o para un tercero;

d. El aprovechamiento doloso u ocultación de bienes provenientes de cualesquiera de los actos a los que se refiere el presente artículo; y

e. La participación como autor, co-autor, instigador, cómplice, encubridor o en cualquier otra forma en la comisión, tentativa de comisión, asociación confabulación para la comisión de cualquiera de los actos a los que se refiere el presente artículo.

2. La presente Convención también será aplicable, de mutuo acuerdo entre dos o más Estados Partes, en relación con cualquier otro acto de corrupción no contemplado en ella.

21 La Convención señala en su artículo VIII el soborno transnacional:

Con sujeción a su Constitución y a los principios fundamentales de su ordenamiento jurídico, cada Estado Parte prohibirá y sancionará el acto de ofrecer u otorgar a un funcionario público de otro Estado, directa o indirectamente, por parte de sus nacionales, personas que tengan residencia habitual en su territorio y empresas domiciliadas en él, cualquier objeto de valor pecuniario $u$ otros beneficios, como dádivas, favores, promesas o ventajas, a cambio de que dicho funcionario realice $\mathrm{u}$ omita cualquier acto, en el ejercicio de sus funciones públicas, relacionado con una transacción de naturaleza económica o comercial.

Entre aquellos Estados Partes que hayan tipificado el delito de soborno transnacional, éste será considerado un acto de corrupción para los propósitos de esta Convención.

Aquel Estado Parte que no haya tipificado el soborno transnacional brindará la asistencia y cooperación previstas en esta Convención, en relación con este delito, en la medida en que sus leyes lo permitan.

22 La Convención señala en el artículo IX el enriquecimiento ilicito:

Con sujeción a su Constitución y a los principios fundamentales de su ordenamiento jurídico, los Estado Partes que aún no lo hayan hecho adoptarán las medida necesarias para tipificar en su legislación como delito, el incremento del patrimonio de un funcionario público con significativo exceso respecto de sus ingresos legítimos durante el ejercicio de sus funciones y que no pueda ser razonablemente justificado por él.

Entre aquellos Estados Partes que hayan tipificado el delito de enriquecimiento ilícito, éste será considerado un acto de
Pero la Convención también permite plantear la incorporación de los delitos de corrupción en los que no sea necesario el perjuicio patrimonial, situación que la legislación peruana ha contemplado.

Por tanto, asumir los criterios de la Convención nos permite tener una alternativa para interpretar el artículo 41 de la Constitución in fine, dotándolo de contenido, con lo cual se llevaría a incorporar a los delitos contemplados bajo los alcances de la misma al considerarlos imprescriptibles, dejando a los delitos no comprendidos en la Convención, pero sí regulados en el CP de 1991, con la duplicidad del plazo de prescripción o el régimen común de la prescripción ordinaria o extraordinaria de la acción penal.

Finalmente, la Convención también precisa algunos alcances sobre la aplicación en el tiempo de las reglas penales en el art. XIX ${ }^{23}$, así como del respeto a las reglas penales que no interrumpirá los plazos de prescripción en curso relativos a los delitos anteriores a la fecha de la entrada en vigor de esta Convención.

\section{La perspectiva penal}

Partiendo del plano de la técnica legislativa penal aquí habría que precisar primeramente ¿qué se entiende por supuestos más graves? Si por supuestos más graves, se refiere a una condición previa que permita diferenciar un delito en su modalidad básica de un delito en su modalidad agravada (técnica legislativa tradicional).

También puede darse el caso de un delito en su modalidad agravada, cuando el legislador establece como pena conminada de manera escalonada descendiente o ascendiente, o en varios órdenes o niveles, es decir cuando hay varias circunstancias agravantes con penas

corrupción para los propósitos de la presente Convención. Aquel Estado Parte que no haya tipificado el enriquecimiento ilícito brindará la asistencia y cooperación previstas en esta Convención, en relación con este delito, en la medida en que sus leyes lo permitan.

23 La Convención establece en su artículo XIX referido a la aplicación en el tiempo lo siguiente:

Con sujeción a los principios constitucionales, al ordenamiento interno de cada Estado y a los tratados vigentes entre los Estados Partes, el hecho de que el presunto acto de corrupción se hubiese cometido con anterioridad a la entrada en vigor de la presente Convención, no impedirá la cooperación procesal penal internacional entre los Estados Partes. La presente disposición en ningún caso afectará el principio de la irretroactividad de la ley penal ni su aplicación interrumpirá los plazos de prescripción en curso relativos a los delitos anteriores a la fecha de la entrada en vigor de esta Convención. 
cuantitativamente diferenciadas, o cuando estamos ante un tipo penal cualificado. Será en estos casos el supuesto más grave.

Y por último se puede dar el caso de una mixtura entre el modelo tradicional con el modelo cualificado.

Por ende, en estos casos la interpretación tendrá que considerar si se asume el supuesto plural de todas las agravantes que tengan un tipo básico como condición o presupuesto o solo el caso del supuesto de mayor gravedad, cuando habiendo varias agravantes solo se considera a la agravante con la consecuencia jurídica de mayor gravedad de pena conminada.

Desde la perspectiva de la ciencia penal, la cuestión de los delitos graves se puede plantear recurriendo a la doctrina penal, en la que algún sector de la doctrina señala que todo delito es grave, por eso la clasificación que se propone es de delitos graves y muy graves.

Así planteada la cuestión, la fórmula supuestos más graves del delito puede atenderse en un doble plano o situación alterna, por un lado, partiendo del enfoque de la teoría del delito o partiendo de los alcances de la consecuencia jurídica, esto es, de la pena, o desde la perspectiva de la determinación judicial de la pena.

Aunque, la gran discusión de las fórmulas dependerá en un primer plano de establecer, previamente, a qué delitos alcanzará o comprenderá la prohibición de la prescripción, luego en un segundo plano de la discusión a cuáles de las modalidades de dichos delitos se referirá, a todas o solo algunas.

En consecuencia, desde la perspectiva penal, puede recurrirse a varias fórmulas alternas o complementarias que podrían ayudar a reglamentar la fórmula supuestos más graves establecida en el art. 41 de la Constitución:

1. La fórmula de la parte general en la que el legislador defina los supuestos de delitos más graves, atendiendo a criterios de la teoría del delito (presupuestos de tipicidad tales como el grado de afectación de los bienes jurídicos, los principios afectados, la complejidad de su realización a partir de autores y partícipes, la afectación de circunstancias agravantes genéricas).

2. La fórmula de la parte general en la que el legislador defina los supuestos de delitos más graves, a partir de la consecuencia jurídica (puede tratarse del caso de la pena conminada ${ }^{24}$ y/o tipo de pena, o a partir de la escala de los montos de la pena privativa de la libertad).

3. La fórmula de la parte especial en la que el legislador defina de manera taxativa aquellos delitos que los considera más graves ${ }^{25}$.

4. La fórmula de la parte especial en la que el legislador requiere solo a los supuestos más agravados de los tipos básicos (circunstancias agravantes específicas precisadas en el mismo artículo o por tipos agravados regulados en artículos independientes).

5. Partiendo de la determinación judicial de la pena la fórmula consistirá en dejar los casos de los tercios inferiores y superiores para los casos de delitos y el tercio superior para los casos de los supuestos más graves de los delitos.

24 Laura Zúñiga nos ilustra con un ejemplo de delitos transnacionales que utilizan el criterio de la pena conminada al establecer que "según al art. 2. b) de la Convención de Naciones Unidas sobre Criminalidad Organizada Transnacional, por infracción grabe se entiende aquel comportamiento punible con una pena privativa de libertad más grave. Es decir, él término de referencia es la pena privativa de libertad. También la Decisión Marco 2008/841/JAI de 24 de octubre de 2008 , contempla este requisito de gravedad medido en los mismos términos, en su art. 1" (véase Zúñiga (2009), nota a pie $\mathrm{N}^{\circ} 389$, en la p. 273).

25 Otro ejemplo desde la perspectiva de los delitos transnacionales nos lo proporciona Laura Zuñiga a partir de "la Convención de Naciones Unidas sobre Criminalidad Organizada Transnacional establece que los Estados se comprometen a penalizar en sus ordenamientos juridicos internos determinadas conductas delictivas: participación en un grupo delictivo organizado (art. 5) blanqueo o lavado del producto del delito (arts. 6 y 7), corrupción justicia (art. 23). Ahora bien, aunque la "Acción Común relativa a la participación en una organización delictiva en los Estados miembros de la Unión Europea", de 21 de diciembre de 1998, contempla el requisito de gravedad medido en los mismos términos, en los términos medidos por la Convención de Naciones Unidas, establece también que se consideran delitos graves aquellos que se encuentran en el art. 2 del Anexo de Europol. Los delitos contemplados en el art. 2 son: terrorismo (que entrañe atentados contra la vida, la integridad fisica y libertad de las personas o contra sus bienes), el tráfico ilícito de estupefacientes, tráfico ilícito de material nuclear o radioactivo, tráfico de inmigración clandestina, trata de seres humanos, tráfico de vehiculos robados, el blanqueo de dinero vinculado a los anteriores delitos. Además, el Anexo añade: delitos contra la vida, la integridad física (homicidio voluntario, agresión con lesiones graves), la libertad (secuestro, detención ilegal, toma de rehenes), la propiedad (robos organizados, fraude, estafas, extorsión, etc.), falsificación de moneda y medios de pago, falsificación de documentos y tráfico de documentos falsos, tráfico ilicito de armas, municiones y explosivos, tráfico ilicito de bienes c animales y vegetales protegidas, tráfico ilicito de sustancias hormonales y otros factores de crecimiento, etc." (Zúñiga (2009), nota a pie $\mathrm{N}^{\circ} 390$ p. 273). 
Otra de las cuestiones a precisar siguiendo a Larenz, es el tema de las normas jurídicas aclaratorias delimitadoras para referirse a los supuestos de hecho, a diferencia de las normas jurídicas complementadoras, que se vinculan a las consecuencias jurídicas. En el caso de la imprescriptibilidad el problema principal está en la delimitación del supuesto más graves de los delitos.

\section{EL CASO DEL PROYECTO DE LEY N 2114/2017-CR ${ }^{26}$}

Al ya casi culminar el presente artículo se tomó conocimiento de la presentación de un proyecto de ley cuyo texto es:

Artículo 1. Objeto de la Ley

La presente Ley tiene por objeto desarrollar el contenido del artículo 41 de la Constitución Política del Perú referida al plazo de prescripción y a la imprescriptibilidad de la acción penal para delitos cometidos contra la administración pública.

Artículo 2. Modifica el artículo 80 del Código Penal

Modifícase el artículo 80 del Código Penal en los términos siguientes:

“Artículo 80.- La acción penal prescribe en un tiempo igual al máximo de la pena fijada por la ley para el delito, si es privativa de libertad.

En caso de concurso real de delitos, las acciones prescriben separadamente en el plazo señalado para cada uno.

En caso de concurso ideal de delitos, las acciones prescriben cuando haya transcurrido un plazo igual al máximo correspondiente al delito más grave.

26 Hemos preferido analizar el contenido de este proyecto de manera independiente a lo desarrollado en el punto 7 , en razón a que recién se tuvo conocimiento de la propuesta legislativa presentada por el legislador César Henry Vásquez Sánchez del grupo parlamentario Alianza para el Progreso fecha 15 de noviembre de 2017 , por lo cual no lo pudimos incluir en el desarrollo de la ponencia realizada el $17 \mathrm{de}$ noviembre del mismo año en el auditorio Ella Dumba Temple de la UNMSM, con ocasión del Congreso de Derecho Penal.

Recientemente, también se ha presentado el Proyecto de ley $N^{\circ}$ 2219/2017-CR por el congresista Carlos Tubino Arias Schireiber del Grupo Parlamentario Fuerza Popular, por el cual se pretende declarar la imprescriptibilidad de la reparación civil para los condenados por los delitos de terrorismo, lo cual ameritará otra investigación.
La prescripción no será mayor a veinte años. Tratándose de delitos sancionados con pena de cadena perpetua se extingue la acción penal a los treinta años.

En los delitos que merezcan otras penas, la acción prescribe a los dos años.

En casos de delitos cometidos por funcionarios y servidores públicos contra el patrimonio del Estado o de organismos sostenidos por éste, el plazo de prescripción se duplica.

"La acción penal es imprescriptible en los delitos contemplados en el Título XVIII del presente Código, específicamente en los tipos penales contenidos en los artículos 384 (colusión), 388 (peculado), 389 (malversación), así como los artículos 393, 393-A, 394, 394-A, 395, 395-A, 395$\mathrm{B}$, referido al cohecho y el artículo 401 (enriquecimiento ilícito)".

Aquí se puede apreciar algunos aspectos en torno a la fórmula utilizada.

Una primera cuestión es el hecho de considerar en la propuesta la fórmula de taxativizar los delitos específicos, sin distinguir los tipos penales básicos, sus agravantes específicas y en otros casos las modalidades que presentan dichos delitos. Así mencionaremos las particularidades de cada uno de los delitos considerados.

1. En lo referente al delito de colusión (art. 384 del CP), no distingue los supuestos del tipo base (primer párrafo) de la agravante específica (regulada en el segundo párrafo).

2. La fórmula propuesta se refiere al art. 388 del CP que regula el delito de peculado de uso, lo cual se considera que un error, pues los casos más graves del delito de peculado están regulados en el art. 387 del CP, y lo constituyen el peculado doloso, con su tipo base y sus supuestos agravados, así como el peculado culposo, y estos casos no han sido considerados.

3. Otro de los delitos comprendidos en la fórmula propuesta es el delito de malversación regulado en el art. 389 del CP, que comprende al tipo básico, así como a su circunstancia agravante específica. 
4. También se incluyó al delito de cohecho pasivo propio regulada en el art. 389 del CP en sus tres modalidades.

5. Asimismo, se comprendió al delito de soborno internacional pasivo regulado en el art. 393-A del CP.

6. Se ha considerado además el delito de cohecho pasivo impropio regulado en el art. 394 del CP, en sus dos modalidades.

7. Se incluyó al art. 394-A, supuesto derogado, que hoy ya no forma parte de los delitos de corrupción regulados en el $\mathrm{CP}$, pues el contenido de este artículo ha sido subsumido en el art. 376-A del CP, como una modalidad de abuso de autoridad.

8. Otro supuesto propuesto es el delito de cohecho pasivo específico regulado en el art. 395 en sus dos modalidades.

9. Se consideró también en el delito de cohecho pasivo propio en el ejercicio de la función policial en sus tres modalidades, regulado en el art. 395-A del CP.

10.Además, se incluyó en la propuesta el delito de cohecho pasivo impropio en el ejercicio de la función policial en sus dos modalidades, regulado en el art. 395-B del CP.

11.Por último, la propuesta contempló al delito de enriquecimiento ilícito regulado en el art. 401 del CP tanto en su tipo base como en la circunstancia agravante específica.

Lo que queda claro también es que la fórmula propuesta prácticamente deja sin contenido los casos en que se produciría la aplicación de la duplicidad del plazo de prescripción de la acción penal, como por ejemplo los delitos de tráfico de influencias, negociación incompatible, las otras modalidades del cohecho, como la corrupción pasiva de los auxiliares jurisdiccionales, el cohecho activo genérico, el cohecho activo transnacional, el cohecho activo específico, el cohecho activo en el ámbito de la función policial.

Otra observación que se contempla es el hecho de haber establecido un listado de delitos realizados por funcionarios $y$ servidores públicos dejando de regular aquellos supuestos de delitos cometidos por particulares, que la fórmula constitucional ahora establece, dejando entrever que para estos casos el plazo no prescribe, sino el plazo se podría duplicar o solo aplicar la prescripción ordinaria y/o extraordinaria.

\section{¿LA PROHIBICIÓN DE LA PRESCRIP- CIÓN O IMPRESCRIPTIBILIDAD DE LA ACCIÓN PENAL Y DE LA EJECUCIÓN DE LA PENA?}

Otro de los inconvenientes que presenta el texto de la regla penal constitucional de la reforma es ¿qué hacer con la prescripción de la ejecución de la pena cuando el texto solo se refiere a la prohibición de la prescripción de la acción penal?

Empero, no se menciona el caso de la prohibición de la prescripción de la ejecución de la pena, con lo cual puede generar una doble interpretación. La primera, de si es posible que el o los condenados por los delitos en su supuestos más graves, tengan la posibilidad de alcanzar la prescripción de la ejecución de la pena, y la segunda, la otra fórmula compleja que sí admite la prohibición de la prescripción de la ejecución de la pena, asumiendo que como el sistema de prescripción de la ejecución de la pena, se basa en el modelo de la prescriptibilidad de la acción penal, entonces no era necesario mencionarla, pues si la acción penal de algunos delitos en sus supuestos más graves no es prescriptible, entonces lo mismo acontecerá con el supuesto de prescripción de la ejecución de la pena, es decir para los condenados por delitos en los supuestos más graves no son prescriptibles la ejecución de sus penas, ello considerando lo señalado en el punto 5 in fine.

\section{CONCLUSIONES}

La regla penal constitucional regulada en el último párrafo del art. 41 de la Constitución de 1993 a partir de la vigencia de la ley $\mathrm{N}^{\circ} 30650$, es de aplicación derivada o de desarrollo y no directa, razón por la cual el Congreso de la República y los congresistas en particular no deben omitir su función de regularla en atención a clarificar y evitar su inaplicación, así como también evitar cualquier tipo de antinomias, sobre todo los casos de duplicidad del plazo de prescripción con los casos de prohibición de la prescripción. 
Otra de las conclusiones es que se clarifique qué se entiende por los supuestos más graves de los delitos que atenten contra el patrimonio del Estado, tanto para funcionarios y servidores públicos, como para particulares en la perspectiva penal para cualquiera de sus manifestaciones; o desde la perspectiva de la Convención Interamericana contra la corrupción.

Se debe aprovechar la oportunidad para corregir las omisiones que la regla penal constitucional no incorporó en el artículo 41 de la Constitución, último párrafo.

\section{FUENTES DE INFORMACIÓN}

\section{Fuentes bibliográficas}

Ramón Capella, J. (1999). Elementos de análisis jurídico. Valladolid, España: Trotta.

Derrida, Jacques (2015). Perdonar, Lo imperdonable y lo imprescriptible. Seguido de Aporéticas del perdón de Diego S. Garrocho y Jorge Pérez de Tudela. Madrid, España: Avarigani.

Cerrada Moreno, M (2018). Prescripción e imprescriptibilidad de los delitos. Barcelona, España: Bosch.

García Belaunde, D. (2016). Las constituciones del Perú. Tercera edición revisada, corregida y aumentada. Lima, Perú: Fondo Editorial de Jurado Nacional de Elecciones.

García-Escudero Márquez, P. (2011). Manual de Técnica legislativa. Madrid, España: Civitas.

Gil Gil,A. (2016). Derechopenal internacional. Madrid, España: Dykinson.

Guastini, R. (2016). Las fuentes del derecho. Fundamentos teóricos (Trad. C. E. Moreno More y L. Cárdenas Rodríguez). Lima, Perú: Raguel ediciones.

Guastini, R. (2007). Teoría e ideología de la interpretación constitucional. Madrid, España: Trotta.

Huertas Díaz, Omar (2013). El debate de la imprescriptibilidad de los delitos de lesa humanidad en Colombia: Análisis desde la perspectiva de los derechos humanos. En
Revista Pensamiento Jurídico, N ${ }^{\circ}$ 37, MayoAgosto, Bogotá-Colombia, 2013, p. 25.

Jankelévitch, Vladimir (1986). Lo imprescriptible, Barcelona-España, Muchnik Editores.

Larenz, K. (1980). Metodología de la ciencia del derecho (4 ${ }^{\mathrm{a}}$ ed.). Barcelona, España: Ariel.

Orozco Pardo, G. y González de Patto, R. M. (Dir.). (2015). Tratado de mediación en la resolución de conflictos. España: Tecnos.

Las constituciones del Perú (2017). Con el estudio preliminar de Carlos Ramos Nuñez. Lima-Perú. Biblioteca Jurídica del Bicentenario. Tribunal Constitucional del Perú, Centro de Estudios Constitucionales y el Ministerio de Justicia y Derechos Humanos, Centro de Estudios en Justicia y Derechos Humanos.

Sáenz Torres, A. D. (noviembre, 2016). Algunas reflexiones a propósito de la intención de regular la imprescriptibilidad para algunos delitos en la Constitución Política del Perú. Gaceta penal y procesal penal, $N^{\circ} 89$, pp. 313330.

Zúñiga Rodríguez, L. (2009). Criminalidad organizada y sistema de derecho penal (Colección estudios de derecho penal y criminología). España: Comares.

\section{Fuentes electrónicas}

Tribunal Constitucional (2004). Exp. $\mathrm{N}^{\circ}$ 047-2004-AI-TC, Pleno Jurisdiccional. Recuperado del sitio de internet: http:// webcache.googleusercontent.com/ search? $q=$ cache:http://www.tc.gob.pe/ jurisprudencia/2006/00047-2004-AI.html

Sáenz Torres Alexei Dante (2012). La prescripción penal en el Perú (A veinte años de vigencia del Código Penal de 1991). (Tesis para optar el título de Magister). Universidad Nacional Mayor de San Marcos. Lima, Perú. Enlace en cybertesis: http://cybertesis.unmsm. edu.pe/bitstream/handle/cybertesis/7980/ Saenz_ta.pdf? sequence $=1$ \&isAllowed $=y$ 